\title{
A Fractional High-Gain Nonlinear Observer Design-Application for Rivers Environmental Monitoring Model
}

\author{
Abraham Efraim Rodriguez-Mata ${ }^{1, *} \mathbb{1}$, Yaneth Bustos-Terrones ${ }^{1}{ }^{(D)}$, Victor Gonzalez-Huitrón ${ }^{1}{ }^{1}$, \\ Pablo Antonio Lopéz-Peréz ${ }^{2}$, Omar Hernández-González ${ }^{3}$ and Leonel Ernesto Amabilis-Sosa ${ }^{1}$ (I) \\ 1 Conacyt-Tecnológico Nacional de México \Instituto Tecnológico de Culiacán, Juan de Dios Bátiz 310, \\ Col. Guadalupe, Culiacán Rosales CP 80220, Sinaloa, Mexico; yabustoste@conacyt.mx (Y.B.-T.); \\ victor.gonzalez@itculiacan.edu.mx (V.G.-H.); lamabilis@conacyt.mx (L.E.A.-S.) \\ 2 Escuela Superior de Apan, Universidad Autonoma de Hidalgo, Carretera Apan-Calpulalpan s/n, Colonia, \\ Chimalpa Tlalayote 43920, Hidalgo, Mexico; save1991@yahoo.com.mx \\ 3 Conacyt-Tecnológico Nacional de México $\backslash$ Instituto Tecnológico de Hermosillo, Av. Tecnológico y, \\ Periférico Poniente S/N, Sahuaro, Hermosillo 83170, Sonora, Mexico; ohernandezg@conacyt.mx \\ * Correspondence: aerodriguez@conacyt.mx
}

Received: 2 June 2020; Accepted: 10 July 2020; Published: 16 July 2020

\begin{abstract}
The deterioration of current environmental water sources has led to the need to find ways to monitor water quality conditions. In this paper, we propose the use of Streeter-Phelps contaminant distribution models and state estimation techniques (observer) to be able to estimate variables that are very difficult to measure in rivers with online sensors, such as Biochemical Oxygen Demand (BOD). We propose the design of a novel Fractional Order High Gain Observer (FOHO) and consider the use of Lyapunov convergence functions to demonstrate stability, as it is compared to classical extended Luenberger Observer published in the literature, to study the convergence in BOD estimation in rivers. The proposed methodology was used to estimated Dissolved oxygen (DO) and BOD monitoring of River Culiacan, Sinaloa, Mexico. The use of fractional order in high-gain observers has a very effective effect on BOD estimation performance, as shown by our numerical studies. The theoretical results have shown that robust observer design can help solve problems in estimating complex variables.
\end{abstract}

Keywords: Streeter-Phelps model; fractional-order control; high observers; river monitoring

\section{Introduction}

Among the main problems of humanity are those related to water availability and pollution. Unfortunately, industrial development and population growth lead to an increase in pollutant discharges which have a negative impact mostly on aquatic ecosystems [1]. With the accelerated urbanization in the world, and especially in Mexico, environmental water problems have become even more considerable. Long-term ineffective governance has driven to aggravate water pollution in some areas more than ever before [2]. In recent years, with importance on environmental water quality, water pollution has been gradually brought under control. In addition, research has been centred on the field of water quality exploration and pollutant diffusion simulation in rivers and watersheds via mathematical modeling and novel tech [3].

Related to aquatic environments researches, the water quality model is a fundamental strategy for the water study and its forecasts. Streeter-Phelps model is distinguished as the first dynamic and spatial water quality model. Therefore, almost all modern timeline researchers have done an enormous amount of research in improving and developing water quality models [4]. Due to their relevance, 
experts in environmental river control are still employing it to obtain mathematical models of water quality from rivers and lakes [5-9].

The Streeter-Phelps model relates the two main mechanisms that define dissolved oxygen in a lotic water Biochemical Oxygen Demand (BOD) receiving wastewater tributary. These mechanisms are a decomposition of organic matter and oxygen aeration [5]. It is also used to estimate BOD and Dissolved oxygen (DO) transport, which is achieved by feeding data on hydromorphological and water quality parameters [10].

Usually, automated water quality control in rivers and lakes is still done traditionally, i.e., employing complicated laboratory techniques, which implies time, consumable resources, and delays in decision-making [11]. Some robotic prototypes have been proposed to obtain a better environmental control [12-14]; these are an excellent tool for active monitoring of water quality since this type of robotic device has embedded sensors of physicochemical parameters of remote-controlled GPS position [15-17]. Currently, existing commercial sensors can measure variables, such as turbidity, $\mathrm{pH}$, temperature, and DO, which help measure water quality in water bodies [14]. Currently, there are remarkable scientific advances in relation to mobile and fixed stations for environmental monitoring of rivers [18-20]. Still, there are water quality variables that are not commonly measured by commercial sensors, such as chemical oxygen demand and BOD [11]. Using the information about the Streeter-Phelps model and algorithms called Observers, it is possible to estimate BOD via the information of other sensors, such as the available DO and longitude (GPS signal). Observers have received several versions and improvements in their performance, over time, in the difficult task of state estimation and parameters in complex systems, but these are still being improved in all their different applications. For example, some outstanding works of each technique, from the first generations linear [21], non-linear [22], adaptive [23], sliding mode [24], non-uniformly observable [25], and discreet observers who can provide good results [26], based on the frequency [27] and high-gain systems [28], have been proposed. There are also applications of its functions and fuzzy techniques for diagnosing sensor faults and multiple applications [29,30]. Currently, the use of fractional techniques and their implementation in state estimation via observers is being arduously studied, since the use of fractional techniques allows to add degrees of freedom in the tuning of the observers [31].

From the knowledge of the authors, there are few published works about the use of observers for Streeter-Phelps states estimation; there is a very outstanding work where it was used as a linear technique and a Luenberger observer for the BOD estimation [32]. This remarkable work was possible due to change in the basis to obtain an observable model. However, given the time in which it was published, obsolete techniques are used that are not robust to parametric changes and in the presence of disturbances.

In this paper, we present a robust Fractional High-Gain Nonlinear Observer design for state estimation in the Streeter-Phelps model published in Reference [32]. Besides, we analyze parametric sensibility via the use of Lyapunov convergence functions. The proposed novel fractional observer design is based on a Lyapunov analysis. The proposal is directed to future work where this kind of algorithms can be embedded and programmed in robotic watercraft to estimate environmental rivers quality water variables. MATLAB Simulink simulations are made to show the advantages of our algorithm over those proposed for similar models. Finally, in conclusion, there are some perspectives and thoughts open to investigation for possible tasks in real time.

\section{Mathematical Model and Problem Statement}

The most common nutrient and oxygen distribution pollutant mathematical model is the Streeter-Phelps system. Since 1925, it has described the oxygen balance in rivers, lakes, and water sources. Although the appearance of more complex models, the Streeter-Phelps model (and its extensions) continues to be one of the most widely used, since it is a relatively simple mathematical model. However, it injects much essential information; despite almost a century since its presentation, it continues to be used [4-10]: Under some assumptions, Streeter-Phelps model helps to estimate and 
measure the main variables for environmental studies, such as BOD and DO, via aquatic robots and algorithms observers programmed, thus improving the environmental monitoring of rivers. Together, $\mathrm{BOD}$ and $\mathrm{DO}$ are the parameters that represent the largest number of pollutants in water bodies. Indeed, the higher the $\mathrm{BOD}$, the lower the amount of $\mathrm{OD}$, which in turn poses a greater risk to aquatic life. Furthermore, the study of these parameters allows us to know the resilience of a river and/or the degree of pollution received by polluting discharges [33]. We propose to use the model in this work under the following assumptions.

\section{Condition 1.}

1. The river maintains a constant volumetric flow rate and possible bounded changes to nominal flow rate (U volume/time).

2. It is assumed that a one-dimensional longitudinal displacement in the same natural direction as the river direction of the river ( $L$ longitude). From $L_{0}=0$ to $L \rightarrow \infty$.

3. It senses dissolved oxygen $\left(x_{1}(L)=x_{1}\right) m_{g} \mathrm{O}_{2}$ /volume) in real-time in an embedded manner.

4. $B O D\left(x_{2}(L)=x_{2}\right) m g O_{2} /$ volume) can be estimated via state or observer estimation techniques, as the $y=x_{1}$ output is available.

5. Based on the literature [34], we will assume that the mathematical models parameters are invariant to time but sensitive to changes in position $L>0$ or other factor as: temperature, flow velocity, etc., i.e., in this paper, we propose $L$ as the independent variable.

Therefore, given the nature of phenomenology, the independent variable throughout this work will be the position $L$. We have the following Streeter-Phelps mathematical model respect position [35]:

$$
\begin{aligned}
& \left.\frac{d x_{1}}{d L}=-\frac{k_{1}(L)}{U} x_{2}+\frac{k_{2}(L)}{U}\left(D_{s}-x_{1}\right)\right) \\
& \frac{d x_{2}}{d L}=-\frac{k_{1}(L)}{U} x_{2}
\end{aligned}
$$

where the parameters $k_{1}(L)>0$ are the BOD removal rate coefficient, $k_{2}(L)>0$ is the reaeration coefficient, and $D_{s}$ is the oxygen saturation level. This type of system tends to be extremely sensitive to parameter changes, in this case, parameters, such as linear velocity $U$ and the variation of constants $k_{1,2}$ [33]. Therefore, it is necessary to perform a parametric sensitivity analysis, which will be substantial to design a state observer. In this paper, we propose such analysis by using stability concepts in the sense of Lyapunov. For the above, it is necessary to make some conceptual assumptions to study stability analysis.

Condition 2. It is proposed that the model parameters (1) fulfilled following condition:

$$
\begin{aligned}
& k_{1}(L)=k_{1}+\beta_{1}(L) \\
& k_{2}(L)=k_{2}+\beta_{2}(L),
\end{aligned}
$$

where $k_{1,2}$ are nominal known parameters; $\beta_{1}(L)$ and $\beta_{2}(L)$ are continuously bounded functions $\left|\beta_{1}(L)\right|<\alpha_{1} l$ and $\left|\beta_{2}(L)\right|<\alpha_{2} L$; and the $\alpha_{1,2}>0$ are Lipschitz constants respect to longitude $L$. In this paper, we propose that $\beta_{1}(L), \beta_{2}(L)$ functions are unknown, unexpected but bounded, which cause unwanted parametric distortion $\delta(L)$. 
Substituting (2) on the mathematical model (1) and reducing:

$$
\begin{aligned}
\frac{d x_{1}}{d L} & =-\frac{k_{1}}{U} x_{2}-\frac{k_{2}}{U} x_{1}+\delta_{1}+\frac{k_{2}}{U} D_{s} \\
\frac{d x_{2}}{d L} & =-\frac{k_{1}}{U} x_{2}+\delta_{2} \\
\delta_{1} & =-\frac{1}{U}\left(-\beta_{1}(L) x_{1}-\beta_{2}(l)\left(D_{s}-x_{2}\right)\right) \\
\delta_{2} & =-\frac{1}{U} \beta_{1}(L) x_{1} .
\end{aligned}
$$

The previous system (3) can be represented in its state form as a autonomous linear system in bounded disturbance presence:

$$
\frac{d x}{d L}=A x+\delta(L)
$$

for $x^{T}=\left[x_{1}, x_{2}\right]^{T}, \delta^{T}(L)=\frac{1}{U}\left[\delta_{1}+k_{2} D_{s}, \delta_{2}\right]^{T}$, and $A=\left[\begin{array}{cc}-k_{2} \frac{1}{U} & -k_{1} \frac{1}{U} \\ 0 & -k_{2} \frac{1}{U}\end{array}\right]$. Hence, a general condition to the global disturbance $\delta(L)$ is proposed.

Condition 3. Let $\delta(L)$ be a bounded unknown nonlinear function such that the following is fulfilled:

$$
\|\delta(L)\| \leq D_{\max }>0 .
$$

Note 1. In this paper, we will assume that the linear velocity remains constant, as we focus on the possible change in kinetic, chemical parameters $\left(k_{1,2}\right)$. The parametric distortions due to linear velocity $\left(U_{\text {river }}\right)$ changes will not be treated in this work due to an extension of it. But, it is easy to see that this kind of distortions (linear velocity changes) would cause limited delta distortions; therefore, for $U_{\text {river }}=U_{\text {nom }}+\delta(U) U$ :

$$
\begin{aligned}
\frac{d x}{d L} & =A_{U_{n o m}} x+\delta(U) X \\
\|\delta(U)\| & \leq\left\|A_{U_{n o m}}\right\| .
\end{aligned}
$$

Therefore, the following theoretical result is proposed, where parametric sensitivity is analyzed via a stability analysis using Lyapunov's convergence functions.

Theorem 1. Let $x=0$ be the spatial equilibrium point of $(4)$ and $\delta(L)$ fulfilled above Condition 3 . The origin $x=0$ will maintain a bonded dynamic in a ball of convergence in parametric chances presence for non-negative matrix $Q$ and $P$ such that: $\lambda_{\min }\{Q\}>>2 D_{\max } \lambda_{\max }\{P\}$.

Proof. The following Lyapunov function is proposed: $V=\frac{1}{u} x^{T} P x$ with independent variable $L$, if it replaces the derivatives under trajectories systems:

$$
\begin{aligned}
& \frac{d V}{d L}=\frac{1}{U} \dot{x}^{T} P x+\frac{1}{U} x^{T} P \dot{x} \\
& \frac{d V}{d L}=x^{T}\left(P A+A^{T} P\right) x+2 x^{T} P \delta(t) .
\end{aligned}
$$

Since $A$ of (4) is Hurwitz matrix for $U, k_{1}, k_{2}>0$, then it is $\operatorname{Re} \lambda_{i}>0$ (due to the nature non-negative parametric system). Hence, Lyapunov algebraic equation calculation $P A+A^{T} P=-Q$ is fulfilled.

Therefore, (7) is reduced, with $c=2 D_{\max } \lambda_{\max }\{P\}, \lambda_{\min }\{Q\}=a$ and bounded: 


$$
\begin{aligned}
& \frac{d V}{d L}=-x^{T} Q x+2 x^{T} P \delta(t) \\
& \frac{d V}{d L} \leq-a\|x\|^{2}+c\|x\| \\
& \frac{d V}{d L} \leq-a\|x\|\left(\|x\|-\frac{c}{a}\right) .
\end{aligned}
$$

The higher the value of the system, the faster it will converge in the neighborhood to a ball of convergence such that

$$
\begin{aligned}
& B_{x}=\left\{\|x\| \in \mathbb{R}^{2}:\|x\|<\frac{c}{a}\right\} \\
& B_{x}=\left\{\|x\| \in \mathbb{R}^{2}:\|x\|<\frac{2 D_{\max } \lambda_{\max }\{P\}}{\lambda_{\min }\{Q\}}\right\} .
\end{aligned}
$$

In the disturbances system presence, (4) in spatial equilibrium point will remain Ultimated Bounded [36].

In order to exemplify the previous theorem use, as well as $P, Q$ matrix calculation, we will use real data obtained from literature and be able to make a parametric stability analysis and sensitivity in the theorem above sense. $U=1$ is proposed, and it is assumed that the parameters of $k_{1}, k_{2}$ have a $5 \%$ maximum change from the nominal value.

First, via Condition 2, the maximum bounded is obtained $\left|\beta_{1}(l)\right|=0.05 k_{1, \text { nom }}$ and $\left|\beta_{2}(l)\right|=0.05 k_{2, \text { nom }}$. Thus, by replacing this in (4) with nominal parameters, $k_{1}=0.3$ day $^{-1}$ and $k_{2}=0.06$ day $^{-1}$ of literature [34]. Disturbance vector $\delta(L)$ will be calculated:

$$
\begin{aligned}
& \delta(L)=\left(\begin{array}{c}
\beta_{1}(l) x_{1} \\
\beta_{1}(l) x_{1}-\beta_{2}(t) x_{2}
\end{array}\right) \\
& \delta(L)=\left(\begin{array}{c}
-0.03 x_{1} \\
0.03 x_{1}-0.006 x_{2}
\end{array}\right) .
\end{aligned}
$$

If parameters are substituted, in matrix A (4), it is obtained:

$$
A=\left[\begin{array}{cc}
-0.3 & 0 \\
-0.3 & -0.06
\end{array}\right]
$$

Therefore, there is a $\Lambda=0.05 A$ matrix, such that $\delta(L)=\Lambda x$, such that:

$$
\delta(L)=\underbrace{\left[\begin{array}{cc}
-0.015 & 0 \\
0.015 & -0.003
\end{array}\right]} x
$$

$\Lambda$.

If the matrix $Q=-I$ is chosen, Lyapunov $P$ matrix calculation is obtained by matrix system solution $P A+A^{T} P=-I$, such that:

$$
P=\left[\begin{array}{cc}
1.6667 & -1.3889 \\
-1.3889 & 15.2778
\end{array}\right],
$$

where the eigenvalues of $P$ are $\operatorname{Re} \lambda_{i}=\left[\begin{array}{ll}1.667 & 90.2778\end{array}\right]$, to obtain the convergence ball of (9), in the presence of a constant perturbation of $5 \%$, such that $\lambda_{\max }\{P\}=15.2778, \lambda_{\max }\{Q\}=1$ and $\lambda_{\max }\{\Lambda\}=0.03$. In addition: 


$$
\begin{aligned}
\|\delta(L)\| & =\|\Lambda x\| \\
\|\delta(L)\| & \leq 0.05\|A\|\|x\| \leq 0.05 \lambda_{\max }\{\Lambda\}\|x\| 0.015\|x\| \\
D_{\max } & \leq 0.015\|x\| .
\end{aligned}
$$

Substituting (12) on the inequality calculation (8):

$$
\begin{aligned}
& \frac{d V}{d L} \leq-a\|x\|^{2}+c\|x\| \leq-\lambda_{\min }\{Q\}\|x\|^{2}+2 D_{\max } \lambda_{\max }\{P\}\|x\| \\
& \frac{d V}{d L} \leq-\|x\|^{2}+0.4581\|x\|^{2} \leq-0.5419\|x\|^{2}
\end{aligned}
$$

Since Lyapunov's function $V=\frac{1}{u} x^{T} A x$ and Raleigh's inequality $\frac{U}{\lambda_{\max }\{A\}} V \leq\|x\|^{2}$, it is had:

$$
\frac{d V}{d L} \leq-1.80 V
$$

Therefore, finally:

$$
V=V(0) e^{-1.80 l}
$$

For a constant perturbation, the system reaches asymptotic stability, which is a sub-case of practical stability. When perturbation varies from the position, the system will converge to a ball of convergence in the sense of Reference [36].

\section{Problem Statement}

The system represented in the linear system (4) has analytical properties that do not allow state estimators to be used, since the $y$ output is a signal that does not permit all states reconstruction, due to general observability matrix, has not been full range, and this has already been studied in the literature. Through certain analytical assumptions about the system (4), a non-linear observable system is obtained, with which it is possible to estimate variables via the use of an observer [32]. By assuming a linear relationship between the BOD removal rate and DO, with zero DO giving no decrease in BOD, a new removal rate coefficient is defined by $k_{3}=\frac{k_{1}}{x_{1}}$. These modifications, performed in (1), show:

$$
\begin{aligned}
& U \frac{d x_{1}}{d L}=-k_{1} x_{2}+k_{2}\left(D_{s}-x_{1}\right)+I_{D}-c_{1} x_{1} \\
& U \frac{d x_{2}}{d L}=-k_{3} x_{1} x_{2}+I_{B}-c_{1} x_{2},
\end{aligned}
$$

where $I_{D}$ is the inflow of DO, $I_{B}$ the BOD inflow, $c_{1}$ the oxygen turnover rate due to flow through, and, on the average, $I_{D}=c_{1} x_{1}$ and $I_{B}=c_{1} x_{2}$. Thus, the previous system can be rewritten as follows:

$$
\begin{aligned}
\frac{d X}{d L} & =A_{0} X+f(X) \\
y & =x_{1},
\end{aligned}
$$

where $A_{0}=\left(\begin{array}{ll}0 & 1 \\ 0 & 0\end{array}\right)$, and $f(X)=\left(\begin{array}{c}-x_{2}+\frac{1}{U}\left(-k_{1} x_{2}+k_{2}\left(D_{s}-x_{1}\right)+I_{D}-c_{1} x_{1}\right) \\ \frac{1}{U}\left(-k_{3} x_{1} x_{2}+I_{B}-c_{1} x_{2}\right)\end{array}\right)$.

For robust BOD estimation via the above model, we propose a novel fractional observer, and its analytical design is proposed in the following section.

\section{Design of a Novel Fractional Observer (FOHO)}

Firstly, fractional calculus is the expansion of traditional analysis to derivation and integration operations employing non-integer orders. In this paper, a fractional-order high gain observer (FOHO) 
is proposed in order to estimate non-measurable variables (BOD) of a river basin environmental monitoring problem. The Caputo fractional derivative of order $\beta$ of a function $\phi(L)$ on the positive real half axis is determined. It is important to notice that the notation $D^{-\beta} \phi(L)$ is used, as well as to denote the fractional integral of order $\beta$ of function $\phi(L)$, more precisely $D^{-\beta} \phi(L) \equiv I^{\beta} \phi(L)$ [37]. The definitions of fractional derivative and fractional integral, as stated above, cannot be used in practice; thus, numeric methods, such as the one based on the Grünwald-Letnikov approach, are commonly used. Here, we deal with the same note in terms of the definition of the fragmentary calculation tool as in Reference [38]. Therefore:

$$
I^{\beta} \phi(L)=\frac{1}{\Gamma(\beta)} \int_{0}^{L} \frac{\phi(\tau)}{(L-\tau)^{1-\beta}} d \tau,
$$

where $0<\tau<L$ and $\beta$. Thus, the following fractional observer (FOHO) is proposed for system (14):

$$
\begin{aligned}
\frac{d z}{d L} & =A_{o} z+f(z)+b u+\Lambda(\theta) C^{T} C e+\hat{\delta} \\
\hat{\delta}(L) & =-S \Delta_{\theta}^{-1} I^{\beta} \operatorname{sign}(e)
\end{aligned} .
$$

For $e=Z-X$, it is as follows:

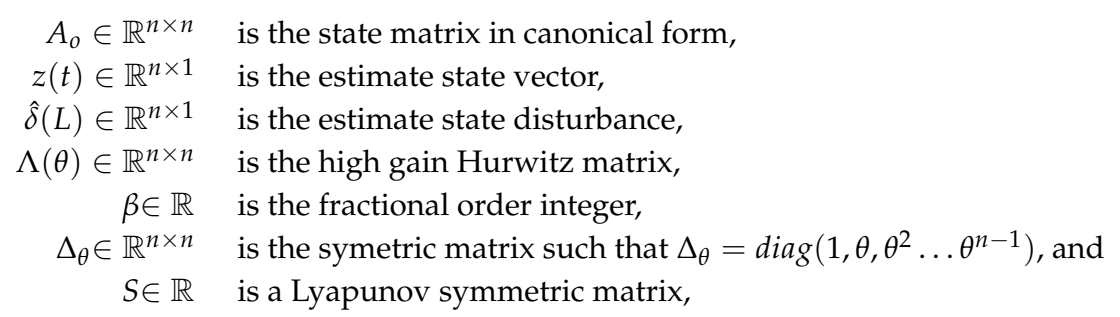

where $h_{1}, \ldots, h_{n}>0$ are gains. $h_{i}$ is an observer gain, $\theta$ is a positive high gain, and $\Lambda(\theta)$ matrix is as follows:

$$
\Lambda(\theta)=\left[\begin{array}{ccccc}
\theta h_{1} & 1 & 0 & \cdots & 0 \\
\theta^{2} h_{2} & 0 & 1 & \ddots & \cdots \\
\vdots & \vdots & \ddots & \ddots & \vdots \\
\theta^{n-1} h_{n-1} & 0 & \cdots & 0 & 1 \\
\theta^{n} h_{n} & 0 & \cdots & 0 & 0
\end{array}\right]
$$

Hence, there is a matrix $A_{h}$ such that it is fulfilled:

$$
\Delta_{\theta}^{-1} \Lambda(\theta) \Delta_{\theta}=\theta A_{h}
$$

There is a symmetric $\Delta_{\theta}$ such that $\Delta_{\theta}=\operatorname{diag}\left(1, \theta, \theta^{2} \ldots \theta^{n-1}\right)$. Thus, $A_{h}$ is a Hurwitz matrix by construction, such that:

$$
A_{h}=\left(\begin{array}{ccccc}
h_{1} & 1 & 0 & \cdots & 0 \\
h_{2} & 0 & 1 & \ddots & \vdots \\
\vdots & \vdots & \ddots & \ddots & 0 \\
h_{n-1} & 0 & 0 & 0 & 1 \\
h_{n} & 0 & 0 & 0 & 0
\end{array}\right)
$$

Condition 4. Let $e=Z-X$ be estimated error such that the following is fulfilled:

1. $A_{h}$ will be a Hurwitz matrix always exists a matrix $S=S^{T}$ such that [39]:

$$
S A_{h}+A_{h}^{T} S=-I .
$$


Therefore, for any $\theta>1$, introduce the next symmetric matrix:

$$
S_{\theta}=\Delta_{\theta}^{-1} S \Delta_{\theta}^{-1} .
$$

2. Consider the error function $e=z-x$ of (16) and (14). Existing $\lambda_{\min }\{S\}=c>0$ such that [40]:

$$
c\left|I^{\beta} \operatorname{sign}(e)\right|>\delta_{\max } .
$$

Therefore, the main general theoretical result of this work is presented by means of the following theorem.

Theorem 2. Convergence of FOHO estimator. Let an observer (16) and (14) be, it is said, that general error of state estimation $e(t)=z(L)-x(L)$ converge asymptomatically, with high gain function $\theta>1$ in unknown nonlinear perturbation presence $|\delta(t)|<D_{\max }$ if $A_{h}$ is a Hurwitz matrix with $D_{\max }$ known, and matrix $C=\left[\begin{array}{lllll}1 & 0 & 0 & \ldots\end{array}\right]$ if it is fulfilled Condition 4.

Proof. The estimate error $\frac{d e}{d L}=\frac{d z}{d L}-\frac{d x}{d L}$ has been substituted in the dynamics Equations (16) and (14) corresponding:

$$
\begin{aligned}
& \frac{d e}{d L}=A_{0} z+b u+\hat{\delta}+\Lambda(\theta) C^{T} C e-A_{0} x-b u-\delta+k(\cdot) \\
& \frac{d e}{d L}=\left(A_{0}+\Lambda(\theta) C^{T} C\right) e+\tilde{\delta}+k(\cdot) \\
& \frac{d e}{d L}=\left(A_{0}+\Lambda(\theta) C^{T} C\right) e+\tilde{\delta}+k(\cdot),
\end{aligned}
$$

where $k(\cdot)=f(Z)-f(X)$ via Lipschitz relationship, and the following condition can be obtained [39], such that: $\|k(\cdot)\| \leq \gamma(z-x) \leq \gamma e$. In addition, it has the following remarkable matrix properties:

$\Lambda(\theta) C^{T} C=\left[\begin{array}{ccccc}\theta h_{1} & 1 & 0 & \cdots & 0 \\ \theta^{2} h_{2} & 0 & 1 & \ddots & \cdots \\ \vdots & \vdots & \ddots & \ddots & \vdots \\ \theta^{n-1} h_{n-1} & 0 & \cdots & 0 & 1 \\ \theta^{n} h_{n} & 0 & \cdots & 0 & 0\end{array}\right]\left[\begin{array}{ccccc}1 & 0 & 0 & \cdots & 0 \\ 0 & 0 & 0 & \ddots & \cdots \\ \vdots & \vdots & \ddots & \ddots & \vdots \\ 0 & 0 & \cdots & 0 & 0 \\ 0 & 0 & \cdots & 0 & 0\end{array}\right]=\left[\begin{array}{ccccc}\theta h_{1} & 0 & 0 & \cdots & 0 \\ \theta^{2} h_{2} & 0 & 0 & \ddots & \cdots \\ \vdots & \vdots & \ddots & \ddots & \vdots \\ \theta^{n-1} h_{n-1} & 0 & \cdots & 0 & 0 \\ \theta^{n} h_{n} & 0 & \cdots & 0 & 0\end{array}\right]$.

Therefore, $A_{0}+\Lambda(\theta) C^{T} C=\left[\begin{array}{ccccc}\theta h_{1} & 1 & 0 & \cdots & 0 \\ \theta^{2} h_{2} & 0 & 1 & \ddots & \cdots \\ \vdots & \vdots & \ddots & \ddots & \vdots \\ \theta^{n-1} h_{n-1} & 0 & \cdots & 0 & 1 \\ \theta^{n} h_{n} & 0 & \cdots & 0 & 0\end{array}\right]=\Lambda(\theta)$

Hence, (21) is modified:

$$
\frac{d e}{d L}=\Lambda(\theta) e+\tilde{\delta}+k(\cdot)
$$

It is proposed a Lyapunov function $V_{\theta}(e)=V_{\theta}$ with its derivates along trajectories of (22):

$$
\begin{aligned}
V & =e^{T} S_{\theta} e \\
\frac{d V}{d L} & =e^{T}\left(S_{\theta} \Lambda(\theta)+\Lambda^{T}(\theta) S_{\theta}\right) e+2 e^{T} S_{\theta} \tilde{\delta}+2 e^{T} S_{\theta} k(\cdot) .
\end{aligned}
$$

Recalling Condition $4 S_{\theta}=\Delta_{\theta}^{-1} S \Delta_{\theta}^{-1}, e_{\theta}=\Delta_{\theta}^{-1} e$, and $e_{\theta}^{T}=\left(\Delta_{\theta}^{-1} e\right)^{T}$ and reshuffling terms: 


$$
\frac{d V}{d L}=e_{\theta}^{T}\left[S \Delta_{\theta}^{-1} \Lambda(\theta) \Delta_{\theta}+\left(\Delta_{\theta}^{-1} \Lambda(\theta) \Delta_{\theta}\right)^{T} S\right] e_{\theta}+2 e_{\theta}^{T} S k(\cdot)+2 e_{\theta}^{T} S \Delta_{\theta}^{-1} \tilde{\delta} .
$$

Replacing (17) on (24):

$$
\frac{d V}{d L}=\theta e_{\theta}^{T}\left[S A_{h}+A_{h}^{T} S\right] e_{\theta}+2 e_{\theta}^{T} S k(\cdot)-2 e_{\theta}^{T} S \Delta_{\theta}^{-1} \tilde{\delta} .
$$

Giving $\tilde{\delta}=\hat{\delta}-\delta$, if we substitute the $\hat{\delta}$ of observer (16):

$$
\frac{d V}{d L}=\theta e_{\theta}^{T}\left[S A_{h}+A_{h}^{T} S\right] e_{\theta}+2 e_{\theta}^{T} S k(\cdot)-2 e_{\theta}^{T} S \Delta_{\theta}^{-1}\left(2 S \Delta_{\theta}^{-1} I^{\beta} \operatorname{sign}(e)-\delta\right) .
$$

Given that $A_{h}$ is a Hurwitz matrix and $\|\delta\| \leq D_{\max }$ and fulfilling Condition 4 , it has, as follows:

$$
\begin{aligned}
& \frac{d V}{d L}=-\theta e_{\theta}^{T} e_{\theta}+2 e_{\theta}^{T} S k(\cdot)-2 e_{\theta}^{T} S \Delta_{\theta}^{-1}\left(2 S \Delta_{\theta}^{-1} I^{\beta} \operatorname{sign}(e)-\delta\right) \\
& \frac{d V}{d L}=-\theta e_{\theta}^{T} e_{\theta}+2 e_{\theta}^{T} S k(\cdot)-e_{\theta}^{T} S \Delta_{\theta}^{-1}\left(S \Delta_{\theta}^{-1} I^{\beta} \operatorname{sign}(e)-\delta\right) \\
& \frac{d V}{d L} \leq-(\theta-b)\|e\|_{\theta}^{2}+c\|e\|_{\theta}\left(c\left\|I^{\beta} \operatorname{sign}(e)\right\|-D_{\max }\right) .
\end{aligned}
$$

Since $\lambda_{\max }\left\{\Delta_{\theta}^{-1}\right\}=1$ for one high gain $\theta \gg b$, where $b=2 \lambda_{\min }\{S\} \lambda_{\min }, c=$ $\lambda_{\max }\{S\} \lambda_{\max }\left\{\Delta_{\theta}^{-1}\right\}=\lambda_{\min }\{S\}$, the observer will converge asymptomatically to zero when the longitude tends to infinity, in same sense as Reference $[37,40]$.

\section{Materials and Methods}

In order to carry out the numerical simulation study, it is necessary to mention the conditions and system parameters to be studied, in this case, an urban river in Mexico. All these data were obtained from the literature; thus, it is possible to carry out a theoretical numerical simulation to be able to appreciate the $\beta$ parameter observer effect on the BOD estimate in the river simulation. The Culiacán river, located in the State of Sinaloa, is of great regional importance since this country region is known as the granary of Mexico, and this river feeds the agricultural industry. Its course is $87.5 \mathrm{~km} \mathrm{long}$, and its basin covers $17,200 \mathrm{~km}^{2}$, with an annual flow of 3280 million $\mathrm{hm}^{3}$. It has an average depth of $1335 \mathrm{~m}$, with an average width of $50 \mathrm{~m}$ and a flow of $0.5 \mathrm{~m}^{3} / \mathrm{s}$ [41,42].

The river is formed at the confluence Tamazula and Humaya rivers. It runs along the Pacific coastal plain, initially flowing through a large part of the urban area, which is why it has been indicated that the Culiacán River has a certain level of pollution resulting from the discharge of contaminated water from industrial processes [43]. Therefore, it is necessary to be able to monitor water quality and its DO and BOD levels. In this section, we suggest a numerical simulation study where we suggested estimation BOD and monitoring of DO in presence to Streeter-Phelps model parameters changes. The modelling parameters are taken from those published in Reference [32], and we will have $100 \% k_{1}$ and $k_{2}$ nominal parameters along the river position $L$, simulating the course of an aquatic boat robot at constant velocity in the environmental monitoring task by measuring $\mathrm{DO}\left(x_{1}\right)$ and estimating BOD $\left(x_{2}\right)$ using the fractional observer shown (16).

In this paper, we performed a simulation study on the use of the Streeter-Phelps model for DO measurement and BOD estimation of the Culiacán river. The simulation was carried out in MATLAB-Simulink language, via a numerical method ODE45 with variable step. Based on the physical data model river parameters (14), the study was carried out using the simulation parameters summarised in the following Table 1. 
Table 1. Model (14) and observer (16) simulation parameters.

\begin{tabular}{cc}
\hline Parameter & Value \\
\hline Nominal $k_{1}$ & $9.6 \mathrm{~L} / \mathrm{mo}$ \\
Nominal $k_{2}$ & $6 \mathrm{~L} / \mathrm{mo}$ \\
$U$ & $7 \mathrm{~km} / \mathrm{mo}$ \\
$I_{D}$ & $347 \mathrm{mg} / \mathrm{L}^{*} \mathrm{mo}$ \\
$I_{B}$ & $197.8 \mathrm{mg} / \mathrm{L}^{*} \mathrm{mo}$ \\
$D_{s}$ & $15.76 \mathrm{mg} / \mathrm{L}$ \\
$x_{1}(0)$ & $10 \mathrm{mg} / \mathrm{L}$ \\
$x_{2}(0)$ & $3.83 \mathrm{mg} / \mathrm{L}$ \\
$z_{1}(0)$ & $10 \mathrm{mg} / \mathrm{L}$ \\
$z_{2}(0)$ & $4.2 \mathrm{mg} / \mathrm{L}$ \\
$h_{1}$ & -1.5 \\
$h_{2}$ & -5 \\
$\theta$ & 2 \\
$\beta$ & {$[0,0.3,0.6,0.9,1]$} \\
$\mathrm{t}$ & $0 \rightarrow 2 \mathrm{~km}$ \\
\hline
\end{tabular}

To test FOHO robustness (16) and Luenberger classical [32] observer algorithms, we noted a parameter change throughout the simulation, recreating changes along river length (see to Figure 1). We suggest changes on the Culiacán nominal Streeter-Phelps parameters from the position or length of the river. It is proposed that the DO signal $\left(x_{1}\right)$ recreates more realistic conditions; therefore, we add a white Gaussian noise signal. Since a theoretical numerical study is presented in this work, the $L=0$ is arbitrary, and the initial conditions of BOD and DO are based on the state-of-the-art. Similarly, it is assumed that there are no additional pollution sources within the $2 \mathrm{~km}$ proposed in this numerical simulation.

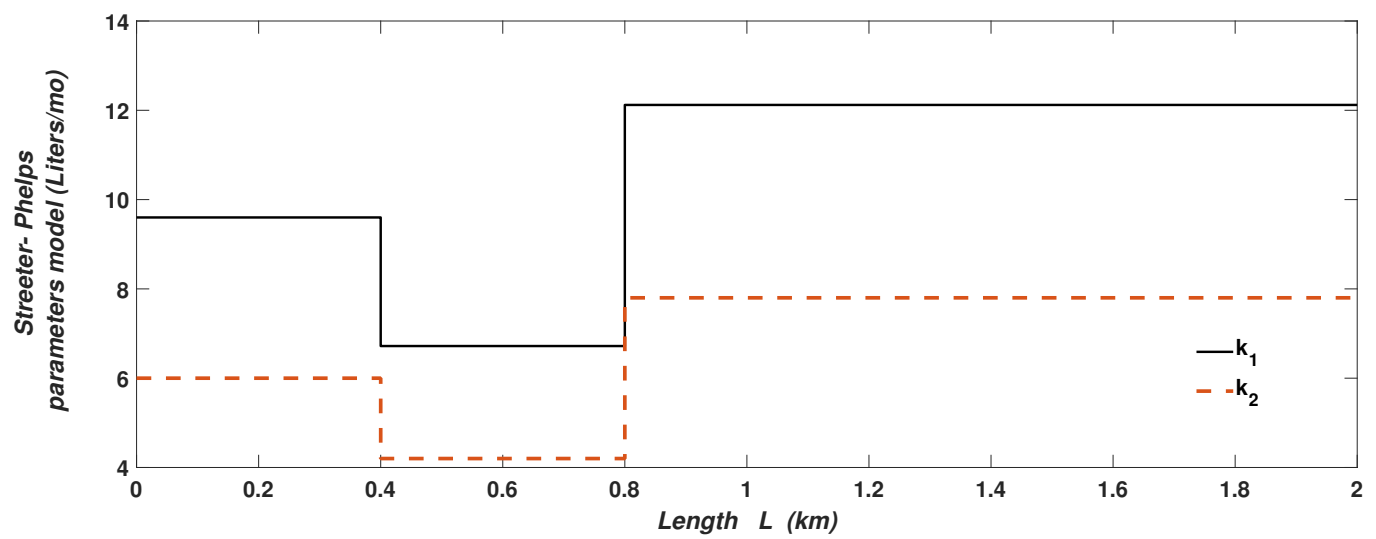

Figure 1. Proposed changes in parameters.

\section{Results}

In this brief chapter, we show the numerical simulation results carried out. We study the effect of the fractional observer order in presence of parameters changed. Simulating the spatial change dynamics in DO and BOD concentrations (see Figures 2 and 3), through that of the FOHO and the classical Luenberger observer [32], we can appreciate $\beta$ parameter change of $\mathrm{FOHO}$; this is unperceivable at a glance. Still, we can significantly understand the FOHO obtains better performance over its classical counterpart. The FOHO (16) rejects Streeter-Phelps parameter changes with significant performance. 


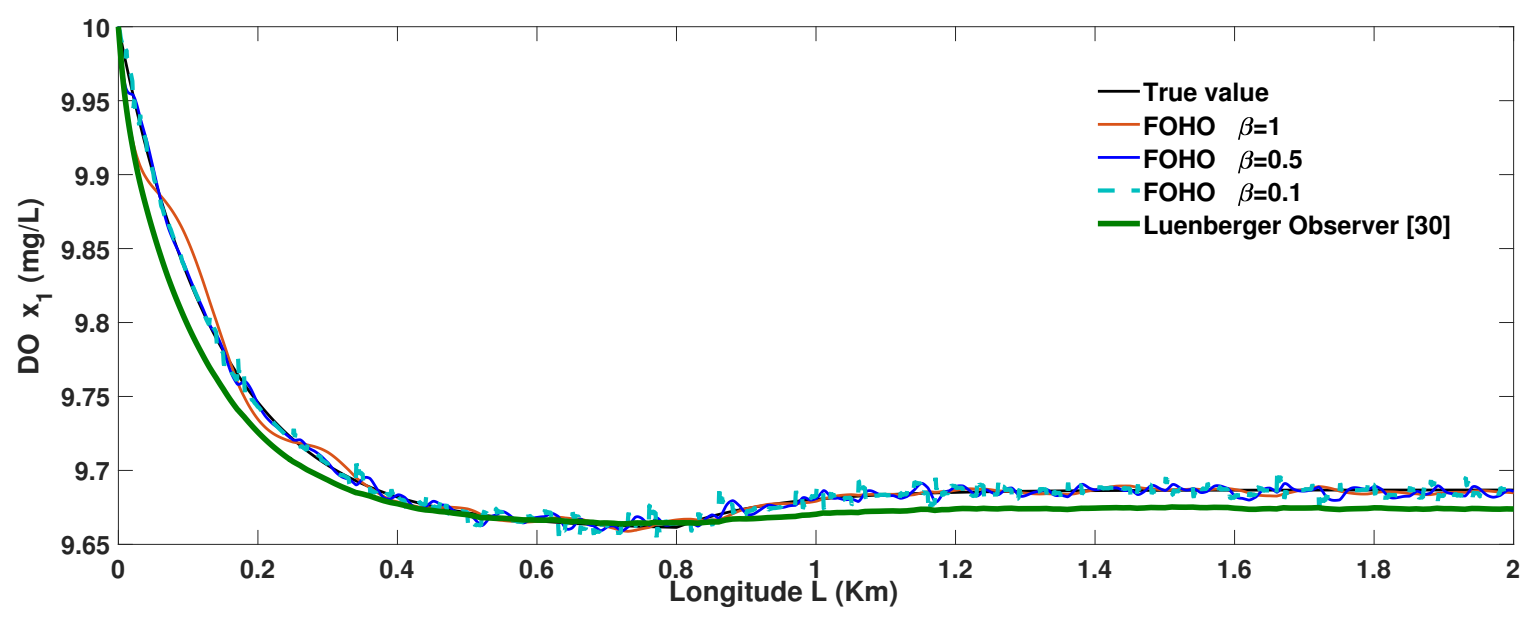

Figure 2. Comparison of Dissolved oxygen (DO) monitoring estimate: the fractional observer (16) and the extended Luenberger classical observer.

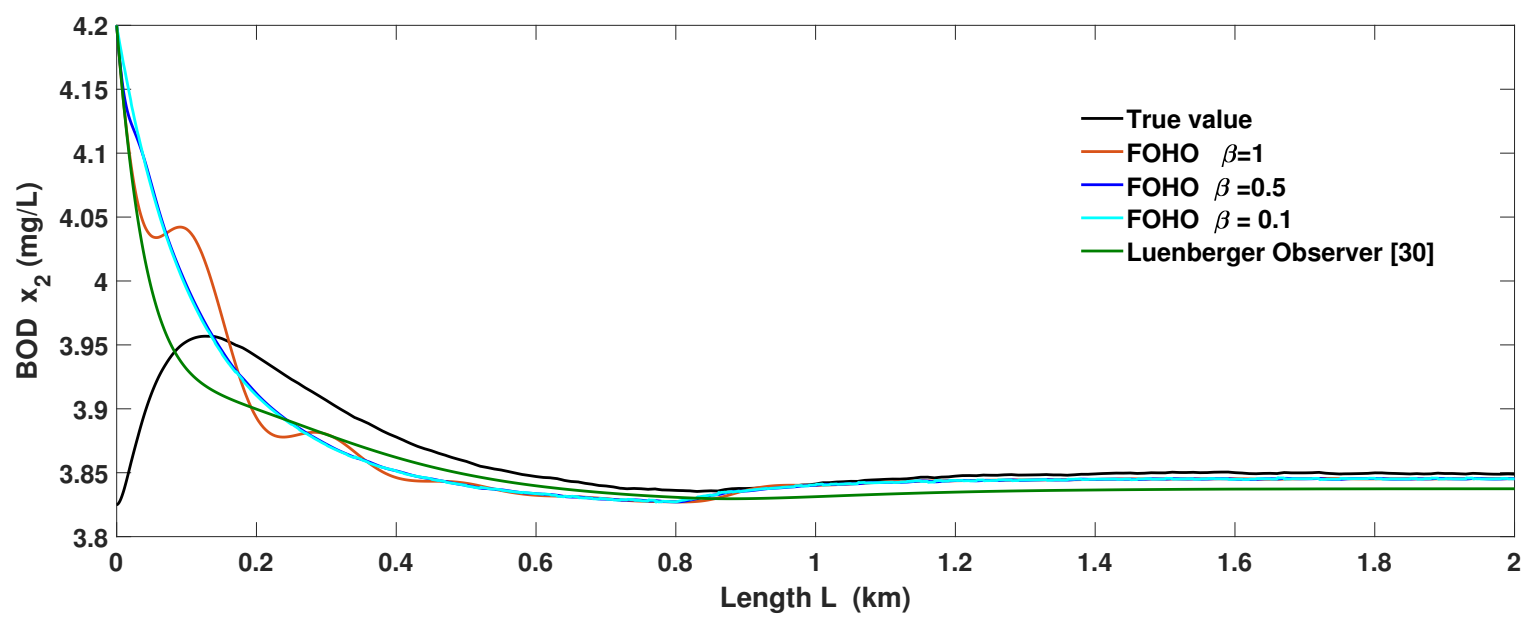

Figure 3. Biochemical Oxygen Demand (BOD) monitoring using observer (16) and its changes depending on $\beta$ fractional-order value and classic observer.

To quantify the performance and accuracy of the state observers, criteria, such as the Integral Distance Absolute error (IDAE), can be used to evaluate the estimation of states in processes of chemical or biochemical character usually used in the evaluation of observers [44-46]. To evaluate the effect of the $\beta$ performance and accuracy of the state observers, we use two different types of error criteria, in same sense as Reference [44].

1. Steady-state performance factor (SSPF) ranges from 0 to 1 , where zero indicates perfect process state reconstruction. Perfect reconstruction in this context means that the process variables in the estimated state vector coincide with the true process. The steady-state performance factor is defined as:

$$
\text { SSPF }=\frac{|x(t)-\hat{x}(t)|}{x(t)},
$$

where $x$ and $\hat{x}$ are evaluated at the steady-state point. Therefore, the SSPF determines the accuracy of a state observer at the steady state [44].

2. Integral Distance Absolute error (IDAE), which is inspired by the criteria shown in Reference [44]. It measures the observer dynamic performance and penalises the errors that persist for long position. In this work, the independent variable is not the time, but it is the length; therefore, the definition is the following: 


$$
I D A E=\int_{0}^{L} L|x(L)-\hat{x}(L)| d L .
$$

To evaluate the effect of the $\beta$ of (16) parameter on state estimation (see to Figure 4), we propose using IDAE and SSPF (see to Figure 5). We can appreciate that, in the presence of noise, a minor fractional-order redeems the value of the IDAE. In the case of classic mode absence, the IDAE is duplicated, proving the superiority of the observer proposed in this work over the classic one.

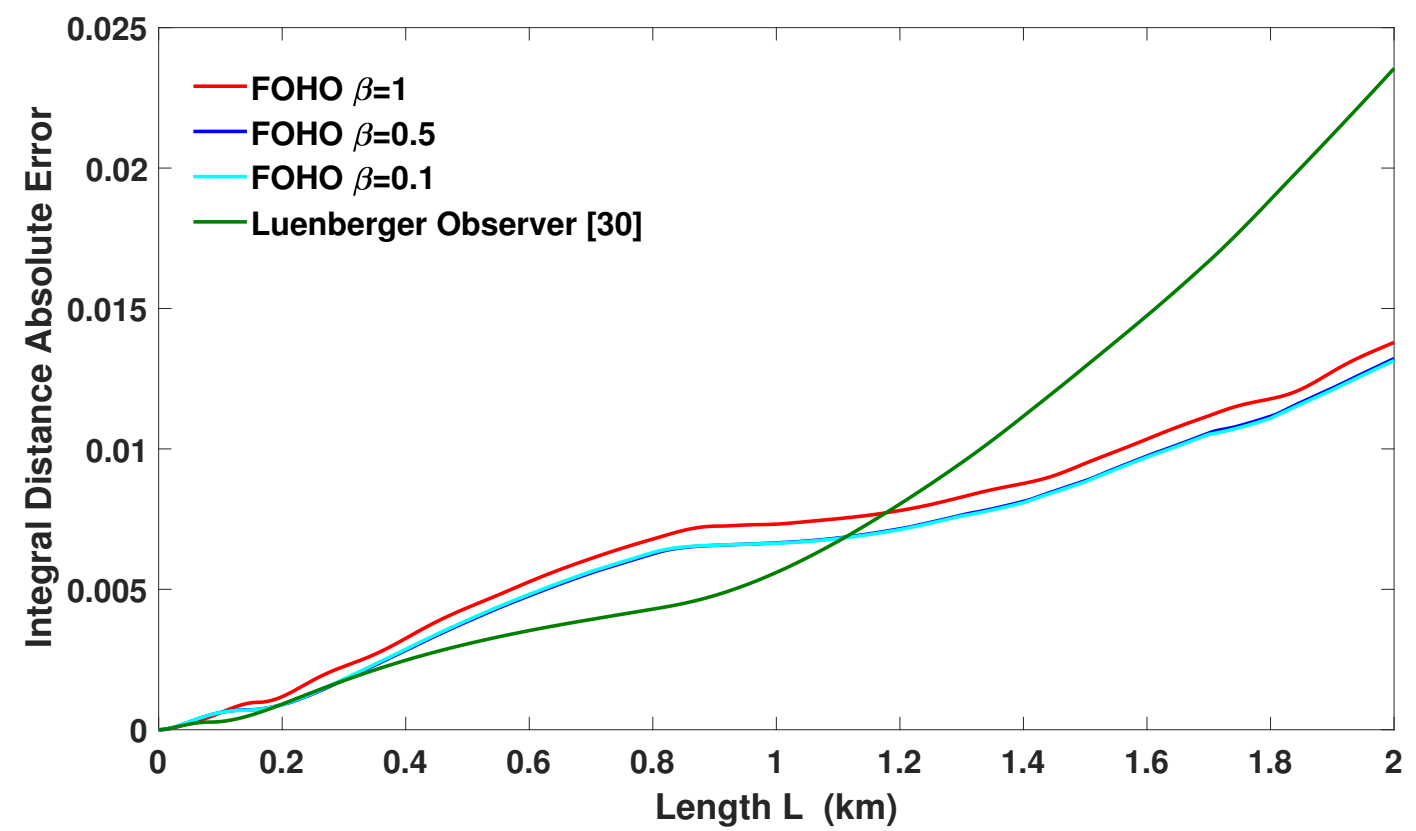

Figure 4. Observers Integral time absolute error (IDAE).

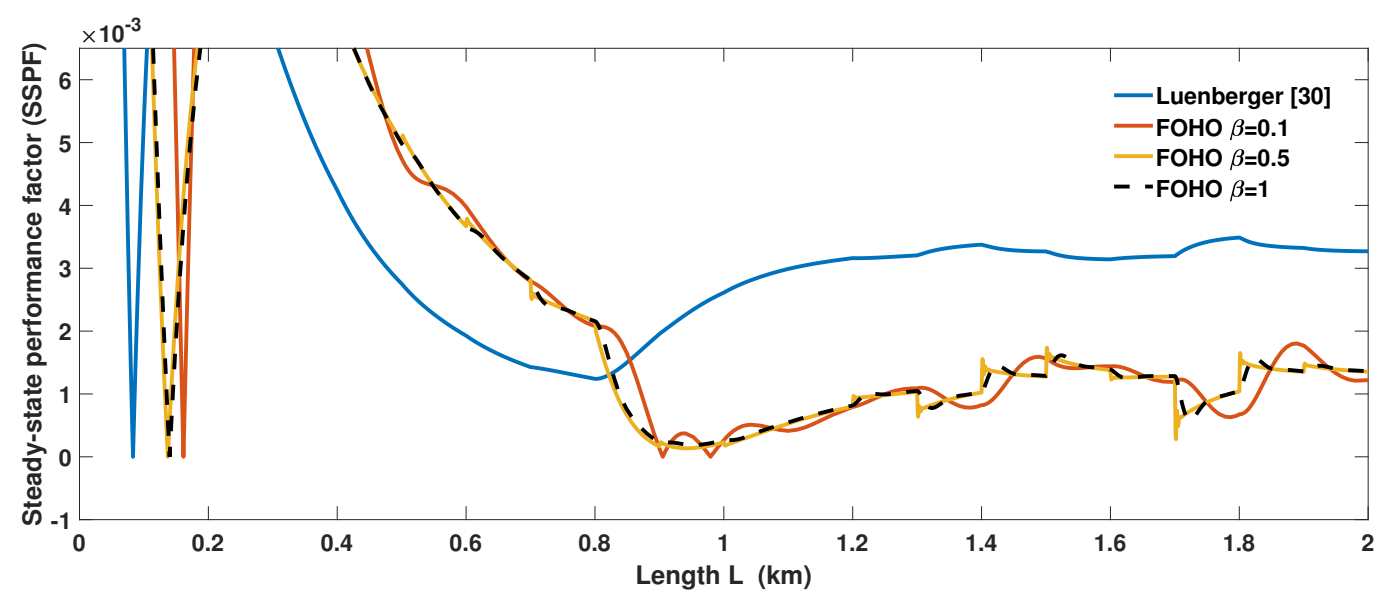

Figure 5. Observers Steady-state performance factor.

In the case of the SSPF, it appreciated a slight effect that has the fractional-order value $(\beta)$, and the value of 0.1 is the one that maintains the best performance, while the classic Luenberger extended has the lowest performance. IDAE criterion importance using specific case is that the independent variable is the $L$ length, and this criterion reflects the net yield from the river length to measure. Before reaching the steady-state, even the extended Luenberger observer [32] maintains a better performance. After $L>1$, when the steady-state is reached, it loses effectiveness due to the parameter changes $k_{1}$ and $k_{2}$ affecting the final value of the steady-state SSPF results, as in Figure 5.

The latest generation of fractional gain observers are superior to the Luenberger Extended versions, in the presence of perturbations at the kinetic constants $k_{1}$ and $k_{2}$. However, high-gain observers 
depend mainly on the structure of the mathematical model. If there is a change in structure, it will result in a type of undefined perturbation, which could not be compensated by the estimator proposed in this paper. Thus, if maximum distortion is greater than the state's maximum, our algorithm would have problems because it is not a fulfilled primary theorem condition, which would be a problem or weakness of our algorithm. Therefore, it could be said that any disturbance that makes the system not comply with Conditions 2 and 3 will make the Fractional observer provided in this paper not perform correctly. When perturbations in parameters, such as $U$ (volumetric flow rate), occur, as long as the condition shown is met, the fractional observer will maintain an excellent performance, since the condition of asymptotic stability of the main theorem is already fulfilled. Fortunately, the parametric and model distortions in most of the real practical cases meet this primary condition.

\section{Conclusions}

In this work, a stability study for Streeter-Phelps model water quality parameters was proposed, where it could be obtained by using Lyapunov functions. The main proposal of this work was to design a new fractional observer to estimate BOD and compare it with the classic form of an extended Luenberger observer. It has been shown that the use of FOHO improves state estimation performance and that the fractional-order plays a critical role in evaluation by analysing the error by the IDAE criteria. This type of algorithm can be used and programmed in waterborne autonomous vehicles to estimate real-time BOD and monitor DO in case of distortions along the water source position. Our laboratory is currently working on this task.

\section{Future Work Perspectives}

The main contribution presented in this work is to provide an algorithm that estimates variables, such as BOD, since there are no on-line sensors for this type of variable [26,47]. This estimating algorithm (dynamic observers) in a robotic water vehicle could be programmed, and, then, the boat robot must include a position sensing unit; some works have shown the ability to have autonomy in the position control via GPS signal $[26,48]$

The vehicle maintains an automatic GPS position control ( $L$ longitude) that allows it to keep a constant speed ( $U$ volume/time), similar to those of the river ( $U_{\text {river }}$ volume/time), as well as an intelligent system of obstacle avoidance that allows the vehicle to stay in the average radius of the river width; hence, $U=U_{\text {river }}$, see Figure 6 . In addition, we propose that these results be presented in a comparative study with renowned modern, robust techniques [29,30] where the performance at parametric and river spatial velocity presence is studied.

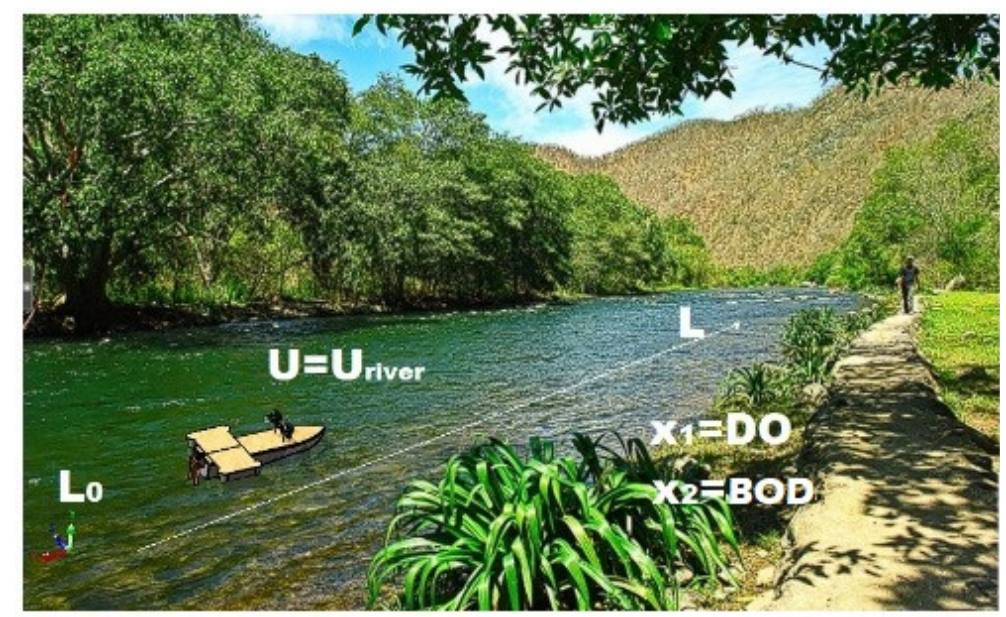

Figure 6. Outline of the application of environmental monitoring. 
Author Contributions: Conceptualization, A.E.R.-M.; methodology, V.G.-H., P.A.L.-P. and O.H.-G.; writing-original draft preparation, Y.B.-T. and L.E.A.-S. All authors have read and agreed to the published version of the manuscript.

Funding: This research received no external funding.

Conflicts of Interest: The authors declare no conflict of interest.

\section{References}

1. Finger, M.; Princen, T. Environmental NGOs in World Politics: Linking the Local and the Global; Routledge: Abingdon, UK, 2013.

2. Wang, J.; Da, L.; Song, K.; Li, B.L. Temporal variations of surface water quality in urban, suburban and rural areas during rapid urbanization in Shanghai, China. Environ. Pollut. 2008, 152, 387-393. [CrossRef] [PubMed]

3. Mendivil-Garcia, K.; Amabilis-Sosa, L.E.; Rodríguez-Mata, A.E.; Rangel-Peraza, J.G.; Gonzalez-Huitron, V.; Cedillo-Herrera, C.I.G. Assessment of intensive agriculture on water quality in the Culiacan River basin, Sinaloa, Mexico. Environ. Sci. Pollut. Res. 2020. [CrossRef] [PubMed]

4. Vellidis, G.; Barnes, P.; Bosch, D.; Cathey, A. Mathematical simulation tools for developing dissolved oxygen TMDLs. Trans. ASABE 2006, 49, 1003-1022. [CrossRef]

5. Chinh, L.V.; Hiramatsu, K.; Harada, M.; Cuu, N.; Lan, T.T. Estimation of Water Environment Capacity in the Cau River Basin, Vietnam using the Streeter-Phelps Model. J. Fac. Agric. Kyushu Univ. 2017, 62, 163-169.

6. Long, B.T. Inverse algorithm for Streeter-Phelps equation in water pollution control problem. Math. Comput. Simul. 2020, 171, 119-126. [CrossRef]

7. Chii, P.L.; Rahman, H.A. Application of water quality models to rivers in Johor. In AIP Conference Proceedings; AIP Publishing LLC: Melville, NY, USA, 2017; Volume 1870, p. 060014.

8. Mendes, T.A.; Alves, T.L.; Monteiro, P.R.A. Modelo Streeter-Phelps para estimativa do oxigênio dissolvido em trecho urbano do rio Meia Ponte. Tecnia 2019, 4, 60-77.

9. Yustiani, Y.M.; Wahyuni, S.; Dewi, S.N.F. Determination of maximum bod load using water quality modeling of upstream citarum river. Int. J. GEOMATE 2019, 16, 118-122. [CrossRef]

10. Alva Saldaña, G.S.; Rojas Gonzales, J.A. Estimación del Déficit de Oxígeno Disuelto Usando el Modelo Streeter y Phelps en la Cuenca Baja del Río Moche. Available online: http:/ / repositorio.ucv.edu.pe/ handle/20.500.12692/40048 (accessed on 13 July 2020).

11. Rodríguez-Mata, A.E.; Amabilis-Sosa, L.E.; Roé-Sosa, A.; Barrera-Andrade, J.M.; Rangel-Peraza, J.G.; Salinas-Juárez, M.G. Quantification of recalcitrant organic compounds during their removal test by a novel and economical method based on chemical oxygen demand analysis. Korean J. Chem. Eng. 2019, 36, 423-432. [CrossRef]

12. Melo, M.; Mota, F.; Albuquerque, V.; Alexandria, A. Development of a robotic airboat for online water quality monitoring in lakes. Robotics 2019, 8, 19. [CrossRef]

13. Jorge, V.A.; Granada, R.; Maidana, R.G.; Jurak, D.A.; Heck, G.; Negreiros, A.P.; Dos Santos, D.H.; Gonçalves, L.M.; Amory, A.M. A survey on unmanned surface vehicles for disaster robotics: Main challenges and directions. Sensors 2019, 19, 702. [CrossRef]

14. Jo, W.; Hoashi, Y.; Aguilar, L.L.P.; Postigo-Malaga, M.; Garcia-Bravo, J.M.; Min, B.C. A low-cost and small USV platform for water quality monitoring. HardwareX 2019, 6, e00076. [CrossRef]

15. Nikitakos, N.; Tsaganos, G.; Papachristos, D. Autonomous Robotic Platform in Harm Environment Onboard of Ships. IFAC-PapersOnLine 2018, 51, 390-395. [CrossRef]

16. Aldegheri, S.; Bloisi, D.D.; Blum, J.J.; Bombieri, N.; Farinelli, A. Fast and power-efficient embedded software implementation of digital image stabilization for low-cost autonomous boats. In Field and Service Robotics; Springer: Berlin/Heidelberg, Germany, 2018; pp. 129-144.

17. Kumar, S.; Kumar, H.; Kumar, K.; Hameed, S.; Fatima, K. Real Time Water Quality Monitoring Boat. Multidiscip. Digit. Publ. Inst. Proc. 2018, 2, 1279.

18. Zappalà, G. A software set for environment monitoring networks. WIT Trans. Ecol. Environ. 2004, 69, 1-10. 
19. Zappala, G.; Alberotanza, L.; Crisafi, E. Assessment of environmental conditions using automatic monitoring systems. In Proceedings of the Oceans' 99. MTS/IEEE. Riding the Crest into the 21st Century. Conference and Exhibition. Conference Proceedings (IEEE Cat. No. 99CH37008), Seattle, WA, USA, 13-16 September 1999; Volume 2, pp. 796-800.

20. Zappalà, G. A versatile software-hardware system for environmental data acquisition and transmission. WIT Trans. Model. Simul. 2009, 48, 283-294.

21. Luenberger, D. An introduction to observers. IEEE Trans. Autom. Control 1971, 16, 596-602. [CrossRef]

22. Zeitz, M. The extended Luenberger observer for nonlinear systems. Syst. Control Lett. 1987, 9, 149-156. [CrossRef]

23. Zhu, F. The design of full-order and reduced-order adaptive observers for nonlinear systems. In Proceedings of the 2007 IEEE International Conference on Control and Automation, Guangzhou, China, 30 May-1 June 2007; pp. 529-534.

24. Davila, J.; Fridman, L.; Levant, A. Second-order sliding-mode observer for mechanical systems. IEEE Trans. Autom. Control. 2005, 50, 1785-1789. [CrossRef]

25. Robles-Magdaleno, J.; Rodríguez-Mata, A.; Farza, M.; M’Saad, M. A filtered high gain observer for a class of non uniformly observable systems-Application to a phytoplanktonic growth model. J. Process Control 2020, 87, 68-78. [CrossRef]

26. Cao, Z.; Zhang, R.; Yang, Y.; Lu, J.; Gao, F. Discrete-time robust iterative learning Kalman filtering for repetitive processes. IEEE Trans. Autom. Control. 2015, 61, 270-275. [CrossRef]

27. Torres, L.; Jiménez-Cabas, J.; Gómez-Aguilar, J.F.; Pérez-Alcazar, P. A simple spectral observer. Math. Comput. Appl. 2018, 23, 23. [CrossRef]

28. Rodríguez-Mata, A.E.; González-Hernández, I.; Rangel-Peraza, J.G.; Salazar, S.; Leal, R.L. Wind-gust compensation algorithm based on high-gain residual observer to control a quadrotor aircraft: Real-time verification task at fixed point. Int. J. Control. Autom. Syst. 2018, 16, 856-866. [CrossRef]

29. Gómez-Peñate, S.; Valencia-Palomo, G.; López-Estrada, F.R.; Astorga-Zaragoza, C.M.; Osornio-Rios, R.A.; Santos-Ruiz, I. Sensor fault diagnosis based on a sliding mode and unknown input observer for Takagi-Sugeno systems with uncertain premise variables. Asian J. Control. 2019, 21, 339-353. [CrossRef]

30. López-Estrada, F.R.; Theilliol, D.; Astorga-Zaragoza, C.M.; Ponsart, J.C.; Valencia-Palomo, G.; Camas-Anzueto, J. Fault diagnosis observer for descriptor Takagi-Sugeno systems. Neurocomputing 2019, 331, 10-17. [CrossRef]

31. Alegria-Zamudio, M.; Escobar-Jiménez, R.; Gómez-Aguilar, J.; García-Morales, J.; Hernández-Pérez, J. Double pipe heat exchanger temperatures estimation using fractional observers. Eur. Phys. J. Plus 2019, 134, 496. [CrossRef]

32. Vorce, T.; Mulholland, R. Estimating Oxygen demand in aquatic ecosystems. In Proceedings of the ICASSP'78. IEEE International Conference on Acoustics, Speech, and Signal Processing, Tulsa, OK, USA, 10-12 April 1978; Volume 3, pp. 402-404.

33. Rinaldi, S.; Soncini-Sessa, R. Sensitivity analysis of generalized Streeter-Phelps models. Adv. Water Resour. 1978, 1, 141-146. [CrossRef]

34. Gotovtsev, A. Modification of the Streeter-Phelps system with the aim to account for the feedback between dissolved oxygen concentration and organic matter oxidation rate. Water Resour. 2010, 37, $245-251$. [CrossRef]

35. Chapra, S.C. Surface Water-Quality Modeling; Waveland Press: Long Grove, IL, USA, 2008.

36. Khalil, H.K.; Grizzle, J.W. Nonlinear Systems; Prentice hall: Upper Saddle River, NJ, USA, 2002; Volume 3.

37. Rodríguez-Mata, A.E.; Luna, R.; Pérez-Correa, J.R.; Gonzalez-Huitrón, A.; Castro-Linares, R.; Duarte-Mermoud, M.A. Fractional Sliding Mode Nonlinear Procedure for Robust Control of an Eutrophying Microalgae Photobioreactor. Algorithms 2020, 13, 50. [CrossRef]

38. Tepljakov, A.; Petlenkov, E.; Belikov, J. Gain and order scheduled fractional-order PID control of fluid level in a multi-tank system. In Proceedings of the ICFDA'14 International Conference on Fractional Differentiation and Its Applications 2014, Catania, Italy, 23-25 June 2014; pp. 1-6.

39. Celikovsky, S.; Torres-Muñoz, J.; Rodriguez-Mata, A.; Dominguez-Bocanegra, A.R. An adaptive extension to high gain observer with application to wastewater monitoring. In Proceedings of the 2015 12th International Conference on Electrical Engineering, Computing Science and Automatic Control (CCE), Mexico City, Mexico, 28-30 October 2015; pp. 1-6. 
40. Govea-Vargas, A.; Castro-Linares, R.; Duarte-Mermoud, M.A.; Aguila-Camacho, N.; Ceballos-Benavides, G.E. Fractional order sliding mode control of a class of second order perturbed nonlinear systems: Application to the trajectory tracking of a quadrotor. Algorithms 2018, 11, 168. [CrossRef]

41. Izaguirre-Fierro, G.; Páez-Osuna, F.; Osuna-López, J. Heavy metals in fishes from Culiacan valley, Sinaloa, Mexico. Cienc. Mar. 1992, 18, 143-151. [CrossRef]

42. Ruiz-Fernández, A.C.; Hillaire-Marcel, C.; Ghaleb, B.; Soto-Jiménez, M.; Páez-Osuna, F. Recent sedimentary history of anthropogenic impacts on the Culiacan River Estuary, northwestern Mexico: Geochemical evidence from organic matter and nutrients. Environ. Pollut. 2002, 118, 365-377. [CrossRef]

43. Ruiz-Fernández, A.; Hillaire-Marcel, C.; Páez-Osuna, F.; Ghaleb, B.; Soto-Jiménez, M. Historical trends of metal pollution recorded in the sediments of the Culiacan River Estuary, Northwestern Mexico. Appl. Geochem. 2003, 18, 577-588. [CrossRef]

44. Olanrewaju, M.J.; Al-Arfaj, M.A. Design and implementation of state observers in reactive distillation. Chem. Eng. Commun. 2007, 195, 267-292. [CrossRef]

45. Oliveira, R.; Ferreira, E.; Oliveira, F.; De Azevedo, S.F. A study on the convergence of observer-based kinetics estimators in stirred tank bioreactors. J. Process Control 1996, 6, 367-371. [CrossRef]

46. Paesa, D.; Franco, C.; Llorente, S.; Lopez-Nicolas, G.; Sagues, C. Reset observers applied to MIMO systems. J. Process Control 2011, 21, 613-619. [CrossRef]

47. Wang, K.; Lu, H.; Liu, B.; Yang, J. A high-efficiency and low-cost AEE polyurethane chemo-sensor for Fe3+ and explosives detection. Tetrahedron Lett. 2018, 59, 4191-4195. [CrossRef]

48. Wendeborn, D.; Armstrong, R.; Nowicki, S.; Hill, S. Method for the Automated Docking of Robotic Platforms. U.S. Patent App. 16/669,363, 30 October 2020.

(C) 2020 by the authors. Licensee MDPI, Basel, Switzerland. This article is an open access article distributed under the terms and conditions of the Creative Commons Attribution (CC BY) license (http:/ / creativecommons.org/licenses/by/4.0/). 